diameter of the seed (assuming that the latter can be obtained). To me the observed 'growing-out' means either that structural imperfections are present due to forced growth or (and it may amount to the same thing) that chain branching can somehow be induced during growth. If this view is correct the most perfect one-dimensional crystals will be those which are most acicular, not the more equiaxed shapes which have been prepared, after much effort, to give large area specimens for physical measurement.

Finally if van der Waals bonds are so important should not someone be looking at zero-dimensional crystals - those held together only by van der Waals forces (or at least what are usually thought of as them)? These crystals by definition would not be metallic, of course, unless 'intercalated' (if that were possible) but their transport properties could be interesting. If a suggestion is in order, $\mathrm{GeI}_{4}$ and $\mathrm{SnI}_{4}$ with their brilliant vermilion-red hue do have a most attractive appearance!

1 Greene, R. L., et al., Phys. Rev. Lett., 34, 577 (1975). 2 Jacobsen, C. S., et al., Phys. Rev. Lett., 33, 1559-62 3 Coleman,

( 1973 ).

15, 1905 (1974). 96,7376 (1974).

Deiseroth, H. J., and Schulz, H., Phys. Rev, Lett., 33, 963 (1974).

Williams, J. M., et al., Phys. Rev. Lett, 33, 1079

Boudeueile, M., and Michel, P., Acta Cryst., A28,

Walatka, V. V., et al., Phys. Rev. Lett., 31, 1139 (1973).

\section{Science and religion}

\section{from a Correspondent}

For the past three years there have been a number of informal consultations between scientists who have been concerned to relate their scientific knowledge and modes of study to their religious faith and practice. Those involved decided in 1974 that their deliberations should be more widely known and from April 10 to 12, the 'Science and Religion Forum' was inaugurated, at a meeting at van Mildert College, Durham, devoted to 'The Problem of Consciousness'.

THe problem was introduced by a paper on "reductionism in biology" by $\mathbf{A}$. R. Peacocke (University of Cambridge), who distinguished between different forms (ontological, methodological and epistemological-linguistic) of 'reductionism'-roughly, the analysis and explanation of entities in terms of their component units, for example explaining all biology in terms of physics and chemistry. Some forms of reductionism would be generally agreed as simply required methodologically by scientific research, but others represent a more general position which can determine attitudes to the relation between consciousness and brain states. Mary Hesse (University of Cambridge), expanded this discussion by describing certain non-additive, non-reducible situations in the quantum physics of particles. Higher-order relations can emerge in complex (for example living) systems which, not in any mysterious metaphysical sense, constitute a kind of logical irreducibility. For example, the analogy of programming from computer science could be valuable in providing a non-reductive valid way of talking about consciousness.

T. Appleton, of the University of Cambridge, gave an account of studies on communication and language at various levels in the biological world and, in particular, described recent work on primates, which shows evidence of a higher level of consciousness, based on their ability to communicate through American Sign Language, than previously thought from studies of verbal communicating abilities.

Howard Robinson, of Liverpool University, outlined, for the benefit of a predominantly scientific audience, the state of the mind-body problem in contemporary philosophy which has concerned attempts to make materialism philosophically respectableattempts which though widely canvassed, have made only a limited number of converts and which $\mathrm{Mr}$ Robinson rejected. Some form of materialism was, in fact, that adopted by a number of those who joined in a general discussion session which inevitably focused on the sensitive area of concepts such as 'soul', 'immortality' and 'personal identity' in relation to scientific, philosophical and theological ideas.

Professor John Bowker (University of Lancaster) described the development of religious consciousness in terms drawn from systems analysis and information process. He drew attention to the extent to which religions function as bounded systems of information process, in which resources are made available to human beings for the construction of a life-way from birth to deathand traditionally in religions, through death as well. 'Religion' and 'science' were originally undifferentiated, emerging from the general endeavour of men to defend and maintain the continuity of their life-way in relation to the limitations which circumscribe it. The sense of God is effective and dynamic as an informational resource in the construction of human life : to take an example, it would thus be possible to interpret Jesus as the totally Godinformed person retrieving in the scan of every situation the cues through which the 'sense of God' is stored in human brain-behaviour, and thus himself becoming a resource for the construction of a religiously-informed human being.

At very short notice, the Bishop of Durham, John Habgood, spoke on "religion-and-science and the church". He stressed the need for philosophical sophistication in the science-religion debate; for reconciliation between the idea of continuity assumed by scientists and that of discontinuity implicit in the beliefs of ordinary Christians; and for man's responsibility for nature (including the ethics of research) to be a principal concern of those present.

\section{Two-step transfer reactions between heavy ions}

from $P$. E. Hodgson

LAST year some measurements were made of the differential cross section of the ${ }^{48} \mathrm{Ca}\left({ }^{16} \mathrm{O},{ }^{15} \mathrm{C}\right){ }^{49} \mathrm{Ti}$ reaction at $56 \mathrm{MeV}$ by the Argonne group (Kovar et al., Phys. Rev. Lett., 33, 1611; 1974). This is a strange reaction: at first glance it looks like a one-nucleon transfer reaction, but closer examination shows that the transferred 'nucleon' must carry two charges. The only possible mechanism is thus a series of nucleon transfer reactions equivalent to a transfer of two protons minus one neutron. This might be expected to be very unlikely, but in fact it is found that the cross section of the reaction to the ground state of ${ }^{48} \mathrm{Ti}$ is comparable to that of normal one-nucleon transfer reactions.

In recent years there has been much interest in multistep contributions to nuclear reactions. These are recognised to be of two types: first those that can proceed through the excitation of the target or the residual nucleus by inelastic scattering (Nature, 251, 188; 1974) and second those proceeding by a series of particle transfer processes. Calculations have been made in a variety of ways for both processes, and in many cases it has been found that the inclusion of multistep contributions greatly improves the agreement between theory and experiment.

In most of the reactions studied so far both these processes could conceivably contribute, and it is sometimes not clear which is the dominant one, except in reactions involving highly collective nuclei which are very easily excited by inelastic scattering, so that the first process dominates. The special feature of the $\left({ }^{16} \mathrm{O},{ }^{18} \mathrm{C}\right)$ reaction is that it must proceed by successive particle transfer, and so it furnishes an excellent case to test the multiple particle transfer theories. 